\title{
Improving prospective memory with contextual cueing
}

\author{
Vanessa K. Bowden ${ }^{1} \cdot$ Rebekah E. Smith ${ }^{2} \cdot$ Shayne Loft ${ }^{1}$ \\ Accepted: 1 December 2020 / Published online: 8 January 2021 \\ (C) The Psychonomic Society, Inc. 2021
}

\begin{abstract}
Prospective memory (PM) involves remembering to perform an intended action in the future. Researchers have demonstrated that, under certain conditions, contextual information about when PM performance opportunities are likely to occur can support PM performance while decreasing the cognitive demands of the PM task. The current study builds upon prior work to investigate whether warning participants that a PM-relevant context was approaching would improve the efficiency of PM control processes and benefit PM accuracy. Participants completed an ongoing lexical decision task with an embedded PM task of responding to a target syllable. For context conditions, targets only appeared on trials where letter strings were colored red (PM-relevant context), while PM-irrelevant trials were green. The warning in Experiment 1 was embedded in the ongoing task (trials preceding PMrelevant contexts were colored yellow). In Experiment 2 the warning was separate from the ongoing task (1-s pre-trial red fixation preceding PM-relevant contexts). Context improved PM control efficiency and PM accuracy in both experiments. Context always improved PM accuracy for targets in the second and third trial positions of PM-relevant contexts; however, only the Experiment 2 warning generated an accuracy benefit for targets in the first trial position. Experiment 3 replicated the findings of Experiments 1 and 2 and also confirmed that color change without associated context was not responsible for the current results.
\end{abstract}

Keywords Prospective memory $\cdot$ Context $\cdot$ Costs

\section{Introduction}

Prospective memory (PM) tasks, which require individuals to remember to perform a deferred action at some point in the future, are vital for everyday functioning. PM tasks can be classified in a variety of ways (Kvavilashvili \& Ellis, 1996), with a distinction commonly made between tasks performed at specific times (time-based PM) and tasks performed in response to environmental events (event- and activity-based PM; Brewer et al., 2011; Einstein \& McDaniel, 1990). The current study investigates how contextual information

Vanessa K. Bowden

vanessa.bowden@uwa.edu.au

Rebekah E. Smith

rebekah@olemiss.edu

Shayne Loft

shayne.loft@uwa.edu.au

1 School of Psychological Science, The University of Western Australia, 35 Stirling Highway, Crawley, Western Australia 6009, Australia

2 Department of Psychology, The University of Mississippi, 205 Peabody Hall, University, MS 38677, USA supports performance in event-based PM. Before reviewing recent research on PM and context, we discuss the cognitive demands of PM tasks.

\section{Prospective memory and costs}

In order to provide an appropriate analog to real-world PM tasks, which are typically performed while also carrying out other activities, laboratory PM tasks are embedded in an ongoing task (Einstein \& McDaniel, 1990). Ongoing task performance can provide an index of the cognitive demands of the PM task (Smith, 2003). Individuals with PM task demands are often slower to perform ongoing tasks on non-PM target trials compared to those performing ongoing tasks alone. This is referred to as the "cost" to the ongoing task. Costs are particularly evident for non-focal PM tasks in which the features of the PM target event that need to be detected are not the focus of ongoing task processing (Einstein et al., 2005).

There are several theories regarding what processes underlie costs. For instance, according to the preparatory attentional and memory processes theory (PAM; Smith, 2003, 2010), costs result from individuals engaging in preparatory attentional processes, which occupy resources (Smith, 2017; 
Smith, Hunt, \& Murray, 2017). Similarly, the Dynamic MultiProcess View (DMPV; Scullin, McDaniel, \& Shelton, 2013) claims that costs result from individuals "monitoring" for PM targets. Alternatively, fitting evidence accumulation models to ongoing task accuracy and response-time (RT) data suggests costs reflect that individuals delay ongoing task responses so as to allow more time to assess the potential PM features of stimuli (Delay theory; Heathcote, Loft, \& Remington, 2015; Strickland, Heathcote, Remington, \& Loft, 2017). Since the current study was not designed to disambiguate between these theories, we collectively refer to the aforementioned proposed mechanisms underlying costs on non-target trials using the more theoretically neutral term "PM control processes."

\section{Prospective memory and context}

Given that PM task demands in the real world are often associated with predictable and familiar environmental contexts, individuals may alter the extent to which they allocate

PM control processes according to whether the PM target is likely to be encountered or not (Smith, 2017; Smith et al., 2017; Smith \& Skinner, 2019). Table 1 summarizes the findings of previous studies that have compared event-based PM performance between context and no-context (referred to as "standard" in the current study) conditions. Providing context means PM target occurrence could be predicted by participants based on pre-determined or learned contextual cues (e.g., the appropriate context for performing the delayed intention is known; Smith \& Skinner, 2019). Table 1 does not include previous studies where PM accuracy was not reported, nor does it include studies of time-based PM. Additional summaries can be found in Smith (2017) and Smith and Skinner (2019).

Some researchers have examined context by demarcating the blocks of trials that could contain a PM target event (PMrelevant context) from those that could not (PM-irrelevant context). As can be seen in Table 1, effects of context on ongoing task performance sometimes appear as reductions in cost on the irrelevant trials for the context condition relative to the standard (no-context) condition, other times as increased cost on the relevant trials, and sometimes both occur. Of the studies presented in Table 1, all studies that report effects on ongoing task RTs show at least one of these effects. In addition, some studies have also reported an improvement in PM accuracy when context is provided compared to standard PM conditions (Ball, Brewer, Loft, \& Bowden, 2015; Bowden, Smith, \& Loft, 2017; Kominsky \& Reese-Melancon, 2017; Loft, Finnerty, \& Remington, 2011; Meier, Zimmermann, \& Perrig, 2006).

In other situations, individuals may use progressive contextual information to anticipate the temporal proximity of PM-relevant contexts. For example, if I need to remember to fill a prescription when passing the pharmacy on my way home from work, I will know when I am approaching the pharmacy. Studying this situation experimentally requires a paradigm that allows participants to track context within a single ongoing task block. Smith et al. (2017) did this by presenting university student participants with photographs taken on their campus and asking them to remember to complete "errands" at specific locations. They predicted that presenting photographs in order, as though participants were walking around campus, would allow participants to anticipate the temporal proximity of PM-relevant contexts and that this would affect the PM control processes allocated throughout the task. Results showed that participants who saw the photographs in order had marginally higher PM accuracy and reduced costs relative to participants who were presented with photographs in a random order, but that costs increased for the ordered condition as the PM-relevant target location neared.

In a subsequent study by Bowden et al. (2017), participants made ongoing true/false judgements for simple sentences while maintaining a PM intention to respond differently to four memorized words. PM-relevant contexts were explicitly cued by presenting progressively updating trial numbers at the top of the display. Participants who were told in advance the range of trial numbers in which PM targets could appear showed reduced costs during PM-irrelevant contexts, increased costs during PM-relevant contexts, and higher PM accuracy compared to those not provided with context. Overall then, there is some evidence to suggest that progressive contextual information, such as movement through a familiar space or progress across numbered trials, allows individuals to anticipate the temporal proximity of PM-relevant contexts and use this knowledge to improve their PM performance with more efficient use of PM control processes.

A common element linking studies that have used a blocked or progressive context design is that participants are provided with some degree of warning before the presentation of PM-relevant contexts. There are undoubtedly situations in the real world where there is no warning when ongoing task contexts relevant to the PM task will be encountered. For example, if I plan to give a colleague a message when they call me at work, there is no warning before the phone rings (and also, since it may be somebody else ringing, encountering a PM-relevant context does not necessitate the presence of a target). Lourenço et al. (2013) emulated this situation by asking participants to respond to PM target syllables, which they only presented on word trials in an ongoing lexical decision task. Participants were either told that the PM target could only appear in words (context condition), or in both words and non-words (standard condition). Word and non-word trials were randomly alternated, thus participants could not predict in advance of a given trial whether that trial would represent a PM-relevant context trial. They found that costs decreased in 
Table 1 Studies that compare event-based prospective memory (PM) performance in context and no-context (standard) conditions. See Smith (2017) for a summary of studies investigating the effects of context on ongoing task measures

\begin{tabular}{|c|c|c|c|c|c|}
\hline & Ongoing task & PM targets ${ }^{1}$ & Designation of context ${ }^{2}$ & Ongoing task cost results & PM task accuracy \\
\hline This study & $\begin{array}{l}\text { Lexical } \\
\text { decision }\end{array}$ & $\begin{array}{l}\text { Syllable "tor" } \\
\text { (9) }\end{array}$ & $\begin{array}{l}\text { Within Plus Warning: PM targets } \\
\text { appeared on trials in red. Other } \\
\text { trials were green (irrelevant) or } \\
\text { yellow (warning; Exp. 1). } \\
\text { Warnings in Exps. } 2 \text { and } 3 \text { were } \\
\text { pre-trial fixations }\end{array}$ & $\begin{array}{l}\text { Context reduced costs on irrelevant } \\
\text { trials compared to no context } \\
\text { Context increased costs on relevant } \\
\text { trials compared to no context }\end{array}$ & $\begin{array}{l}\text { Context improved PM overall, } \\
\text { but see text for effects of } \\
\text { target position within the } \\
\text { relevant context }\end{array}$ \\
\hline Ball et al. (2015) & $\begin{array}{l}\text { Lexical } \\
\text { decision }\end{array}$ & $\begin{array}{l}\text { Animal words } \\
\text { (4) }\end{array}$ & $\begin{array}{l}\text { Between: PM targets occurred } \\
\text { during the second of two blocks } \\
\text { of trials }\end{array}$ & $\begin{array}{l}\text { Context did not affect performance } \\
\text { on irrelevant trials } \\
\text { Context increased costs on relevant } \\
\text { trials compared to no context }\end{array}$ & Context improved $\mathrm{PM}^{\mathrm{a}}$ \\
\hline $\begin{array}{l}\text { Ball and Bugg } \\
\quad \text { (2018a) }\end{array}$ & $\begin{array}{l}\text { Lexical } \\
\text { decision }\end{array}$ & $\begin{array}{l}\text { Syllable "tor" } \\
\text { (16) }\end{array}$ & $\begin{array}{l}\text { Within: Trial content not pre-cued, } \\
\text { either word and/or trials starting } \\
\text { with a consonant could contain } \\
\text { PM target }\end{array}$ & $\begin{array}{l}\text { Context reduced cost compared to } \\
\text { no context on irrelevant trials } \\
\text { Context did not affect performance } \\
\text { on relevant trials }\end{array}$ & Context did not improve $\mathrm{PM}^{\mathrm{a}}$ \\
\hline $\begin{array}{l}\text { Ball and Bugg } \\
\qquad(2018 b)^{4}\end{array}$ & $\begin{array}{l}\text { Lexical } \\
\text { decision }\end{array}$ & $\begin{array}{l}\text { Syllable "tor" } \\
\text { (8) }\end{array}$ & $\begin{array}{l}\text { Within (Exps. } 1 \text { and 2): Trials } \\
\text { appeared in either upper or lower } \\
\text { portion of screen and contained } \\
\text { either words or non-words. } \\
\text { Specific condition in Exp. 1, } \\
\text { correctly told target would } \\
\text { appear only in words, general } \\
\text { told could appear in words or } \\
\text { non-words. Specific condition in } \\
\text { Exp. } 2 \text { correctly told that target } \\
\text { would appear only in word in } \\
\text { upper portion, general told words } \\
\text { or non-words, upper or lower } \\
\text { screen. } \\
\text { Between (Exps. } 3 A \text { and } 3 B \text { ): Trials } \\
\text { blocked in sets of eight all lower } \\
\text { or all uppercase and all in either } \\
\text { upper or lower portion of screen. } \\
\text { Same manipulation of specific } \\
\text { versus general instructions }\end{array}$ & $\begin{array}{l}\text { Context reduced costs on irrelevant } \\
\text { trials compared to no context. } \\
\text { Context did not affect performance } \\
\text { on relevant trials }\end{array}$ & $\begin{array}{l}\text { Exps. } 1^{\mathrm{a}} \text { and } 2^{\mathrm{a}} \text { : Context did not } \\
\text { improve PM } \\
\text { Exps. } 3 \mathrm{~A}^{\mathrm{b}} \text { and } 3 \mathrm{~B}^{\mathrm{a}} \text { : Context did } \\
\text { not improve PM }\end{array}$ \\
\hline $\begin{array}{l}\text { Bowden et al. } \\
\quad(2017)\end{array}$ & $\begin{array}{l}\text { True/false } \\
\text { sentences } \\
\text { task }\end{array}$ & Four words (4) & $\begin{array}{l}\text { Proximity: PM targets appeared in } \\
\text { memorized trial number ranges }\end{array}$ & $\begin{array}{l}\text { Context reduced costs on irrelevant } \\
\text { trials compared to no context } \\
\text { Context increased costs on relevant } \\
\text { trials compared to no context }\end{array}$ & Context improved $\mathrm{PM}^{\mathrm{a}}$ \\
\hline $\begin{array}{l}\text { Brewer and } \\
\text { Marsh (2010) } \\
\text { Exp. } 1\end{array}$ & $\begin{array}{l}\text { Lexical } \\
\text { decision }\end{array}$ & $\begin{array}{l}\text { Animal words } \\
\text { (8) }\end{array}$ & $\begin{array}{l}\text { Between: At encoding, PM task } \\
\text { associated with the specific } \\
\text { ongoing task }\end{array}$ & Not reported & Context improved $\mathrm{PM}^{\mathrm{a}}$ \\
\hline $\begin{array}{l}\text { Bugg and Ball } \\
\text { (2017) }\end{array}$ & $\begin{array}{l}\text { Lexical } \\
\text { decision }\end{array}$ & $\begin{array}{l}\text { Syllable "tor" } \\
\text { (8 plus } 1 \text { in } \\
\text { irrelevant } \\
\text { context) }\end{array}$ & $\begin{array}{l}\text { Within: Trials appeared in either } \\
\text { upper or lower portion of screen } \\
\text { and contained either words or } \\
\text { non-words. In specific condition, } \\
\text { participants told that target } \\
\text { would appear only in word in } \\
\text { upper portion }\end{array}$ & $\begin{array}{l}\text { Effects of context on ongoing task } \\
\text { response times varied as a } \\
\text { function of whether the context } \\
\text { cue was deterministic or } \\
\text { probabilistic }\end{array}$ & $\begin{array}{l}\text { Exps. } 1^{\mathrm{b}} \text { and } 2^{\mathrm{b}} \text { : Context did not } \\
\text { improve PM } \\
\text { Exp. 3: Context improved } \mathrm{PM}^{\mathrm{a}} \\
\text { Exps. 1-3: Context had a } \\
\text { detrimental effect when } \\
\text { targets appeared in } \\
\text { unexpected context }\end{array}$ \\
\hline $\begin{array}{l}\text { Cona, Arcara, } \\
\text { Tarantion, and } \\
\text { Bisiacchi } \\
(2015)\end{array}$ & $\begin{array}{l}\text { Determine if } \\
\text { second and } \\
\text { fourth letters } \\
\text { in five-letter } \\
\text { string are the } \\
\text { same }\end{array}$ & $\begin{array}{l}\text { Letter in first, } \\
\text { third, or } \\
\text { fifth } \\
\text { position } \\
\text { was "B" } \\
\text { (15) }\end{array}$ & $\begin{array}{l}\text { Warning: Warning trial had red } \\
\text { background. Predictable } \\
\text { condition told this meant the PM } \\
\text { target would appear in three to } \\
\text { five trials. Unpredictable told red } \\
\text { color was irrelevant }\end{array}$ & $\begin{array}{l}\text { Trend for reduction in response } \\
\text { times on irrelevant trials in the } \\
\text { predictable versus unpredictable } \\
\text { condition } \\
\text { Cost on relevant trials increased for } \\
\text { predictable condition }\end{array}$ & Context did not improve $\mathrm{PM}^{\mathrm{a}}$ \\
\hline $\begin{array}{l}\text { Kominsky and } \\
\text { Reese-Melan- } \\
\text { con }(2017)^{3}\end{array}$ & $\begin{array}{l}\text { Lexical } \\
\text { decision }\end{array}$ & Fruit words (3) & $\begin{array}{l}\text { Between: Participants told that PM } \\
\text { target would occur either before } \\
\text { or after a mid-experiment break }\end{array}$ & $\begin{array}{l}\text { Context did not affect performance } \\
\text { on irrelevant trials } \\
\text { Trend towards increased costs on } \\
\text { relevant trials }\end{array}$ & Context improved $\mathrm{PM}^{\mathrm{a}}$ \\
\hline $\begin{array}{l}\text { Kuhlmann and } \\
\text { Rummel } \\
\text { (2014) }\end{array}$ & Color matching & $\begin{array}{l}\text { Animal words } \\
\text { (12) }\end{array}$ & $\begin{array}{l}\text { Within: Trial context pre-cued by } \\
\text { the shape of a polygon prior to } \\
\text { word onset. In the context } \\
\text { condition, participants told that } \\
\text { target would appear only } \\
\text { following a specific shape }\end{array}$ & $\begin{array}{l}\text { Context did not affect performance } \\
\text { on irrelevant trials } \\
\text { Context increased costs on relevant } \\
\text { trials compared to no context }\end{array}$ & $\begin{array}{l}\text { Context marginally improved } \\
\mathrm{PM}^{\mathrm{a}}\end{array}$ \\
\hline
\end{tabular}


Table 1 (continued)

\begin{tabular}{|c|c|c|c|c|c|}
\hline & Ongoing task & PM targets ${ }^{1}$ & Designation of context ${ }^{2}$ & Ongoing task cost results & PM task accuracy \\
\hline Loft et al. (2011) & $\begin{array}{l}\text { Air traffic } \\
\text { control } \\
\text { (accep- } \\
\text { tances) }\end{array}$ & $\begin{array}{l}\text { Aircraft with } \\
\text { specific } \\
\text { characteris- } \\
\text { tics (20) }\end{array}$ & $\begin{array}{l}\text { Within: PM target aircraft } \\
\text { approached the sector from cued } \\
\text { locations }\end{array}$ & $\begin{array}{l}\text { Context reduced costs on irrelevant } \\
\text { trials compared to no context } \\
\text { Context did not affect performance } \\
\text { on relevant trials }\end{array}$ & Context improved $\mathrm{PM}^{\mathrm{a}}$ \\
\hline $\begin{array}{l}\text { Lourenço and } \\
\text { Maylor (2014) }\end{array}$ & $\begin{array}{l}\text { Detect whether } \\
\text { uppercase } \\
\text { letter is on } \\
\text { left or right } \\
\text { side of } \\
\text { screen }\end{array}$ & $\begin{array}{l}\text { Same letter } \\
\text { appears on } \\
\text { both sides } \\
\text { of screen in } \\
\text { target color } \\
\text { (5) }\end{array}$ & $\begin{array}{l}\text { Within: Trials in target color } \\
\text { appeared either randomly, or } \\
\text { Between: Trials blocked in sets of } \\
\text { eight }\end{array}$ & $\begin{array}{l}\text { Context reduced cost on irrelevant } \\
\text { trials } \\
\text { Context increased cost on relevant } \\
\text { trials }\end{array}$ & Context did not improve $\mathrm{PM}^{\mathrm{a}}$ \\
\hline $\begin{array}{l}\text { Lourenço, White, } \\
\text { and Maylor } \\
\text { (2013) }\end{array}$ & $\begin{array}{l}\text { Lexical } \\
\text { decision }\end{array}$ & $\begin{array}{l}\text { Syllable "tor" } \\
\text { (8) }\end{array}$ & $\begin{array}{l}\text { Within: Trial content not pre-cued, } \\
\text { either word or non-word trials } \\
\text { could contain PM target }\end{array}$ & $\begin{array}{l}\text { Context reduced cost compared to } \\
\text { no context on irrelevant trials } \\
\text { Context did not affect performance } \\
\text { on relevant trials }\end{array}$ & Context did not improve $\mathrm{PM}^{\mathrm{b}}$ \\
\hline $\begin{array}{l}\text { Meier et al. } \\
\text { (2006) Exp. } 2\end{array}$ & $\begin{array}{l}\text { Short-term } \\
\text { memory } \\
\text { (STM) task } \\
\text { for line } \\
\text { drawings } \\
\text { paired with } \\
\text { words }\end{array}$ & $\begin{array}{l}\text { Words naming } \\
\text { musical } \\
\text { instruments }\end{array}$ & $\begin{array}{l}\text { Between: When given PM } \\
\text { instructions, participants in } \\
\text { specific condition told that they } \\
\text { would perform STM task again } \\
\text { and targets appeared in STM } \\
\text { task. No reference to STM task } \\
\text { for general condition }\end{array}$ & $\begin{array}{l}\text { STM performance not analyzed as } \\
\text { a function of the context } \\
\text { manipulation }\end{array}$ & Context improved $\mathrm{PM}^{\mathrm{c}}$ \\
\hline $\begin{array}{l}\text { Smith et al. } \\
\text { (2017) }\end{array}$ & $\begin{array}{l}\text { Determine } \\
\text { number of } \\
\text { people in a } \\
\text { photo }\end{array}$ & $\begin{array}{l}\text { Locations in } \\
\text { photo- } \\
\text { graphs (4) }\end{array}$ & $\begin{array}{l}\text { Proximity: Location photos } \\
\text { presented in the order of a walk } \\
\text { around a college campus } \\
\text { (ordered condition with context) } \\
\text { or in a random order (no context } \\
\text { information) }\end{array}$ & $\begin{array}{l}\text { Context condition showed reduced } \\
\text { cost relevant to no context } \\
\text { condition. Study did not include } \\
\text { a relevant vs. irrelevant block } \\
\text { comparison, but in the context } \\
\text { condition cost increased as the } \\
\text { target locations approached (i.e., } \\
\text { as the PM task became more } \\
\text { relevant) }\end{array}$ & $\begin{array}{l}\text { Context did not improve PM in } \\
\text { Exp. } 1^{\mathrm{b}} \text {, but there was a trend } \\
\text { towards improvement in Exp. } \\
2^{\mathrm{a}} \text {. Third experiment did not } \\
\text { include a no context condition }\end{array}$ \\
\hline
\end{tabular}

${ }^{1}$ Numbers in parentheses indicate total number of PM target events

${ }^{2}$ Between $=$ between blocks of the ongoing task(s) with certain blocks associated with the PM task. Within $=$ PM task associated with specific target types within a block, but cannot predict when given trial type will occur. Warning = warning signals that PM target or relevant trial types will appear soon. Proximity = contextual information allows participants to anticipate upcoming target events

${ }^{3}$ Note that this study included older adults. PM accuracy here refers to that of younger adults to better compare with other studies

${ }^{\text {a }}$ The average number of PM targets missed was greater than one in the no-context condition

b The average number of PM targets missed was less than one target in the no-context condition

${ }^{c}$ Only one target event. Percentage of participants making PM response ranged from $30 \%$ to $55 \%$ in the general conditions

PM-irrelevant contexts (non-word trials) for the context condition compared to the standard condition, but that there was no difference in costs in PM-relevant contexts (word trials), and no improvement in PM accuracy.

\section{The current study}

The current study aims to further develop our understanding of the factors that allow individuals to benefit from context. It is clear from Table 1 that all studies which showed a benefit to PM accuracy were those which contained some type of warning indicating that a PM-relevant context was approaching (proximity cues, designating relevant blocks of trials, and some trial-by-trial designs). However not all warnings were effective, since a number of studies that included a warning did not find a benefit to PM accuracy. In other words, all beneficial findings had warnings, but not all warnings were beneficial. The current study therefore aimed to systematically investigate how warnings can facilitate the use of contextual information and improve PM performance, and how immediate the benefits to PM accuracy can be after the context warning. To do this, we compared PM performance in PM context conditions and standard (no context) PM conditions as a function of where the target appeared within a PM-relevant context, and, in particular, whether the target appeared on the first, second, or third trial of a multi-trial PM-relevant context.

To our knowledge this is the first experiment to examine the effects of context and warnings on PM accuracy as a function of the specific trial location of a target within the relevant context, relative to a no-context control. Lourenço et al. (2013) alternated context randomly trial by trial, thus 
their targets could be in the "first" position of a PM-relevant context, but randomly alternating trial type does not allow for a systematic comparison across trial positions. Cona et al. (2015) used a warning trial but did not compare PM performance as a function of when the target appeared following the single warning trial. Furthermore, Cona et al. did not otherwise distinguish between PM-relevant and PM-irrelevant trials. More recently, Ball, Li, and Bugg (2020) alternated predictable ten-trial length PM-relevant and PM-irrelevant contexts and compared PM accuracy on targets in the first and second positions of PM-relevant contexts. They found no effect of PM target position on accuracy. However, since all participants were provided with context it was not possible to determine whether the ten-trial warning benefitted both first and second position equally, or had no effect at all. Thus, by including multi-trial PM-relevant contexts, which are still unpredictable from the participant's perspective, we can examine the effects of context on PM performance across successive trial positions of the PM-relevant context and gain a more detailed picture of the benefits of warning participants that a PM-relevant context was approaching, compared to providing no context information.

We anticipated that providing a warning should facilitate the timely initiation of control processes such as preparatory attentional processing (Smith, 2017), monitoring (Scullin et al., 2013), or changes in ongoing task response thresholds (Heathcote et al., 2015), which in turn should support improvements in PM performance, but that this benefit may depend on the PM target position within the PM-relevant context. The implications of the effects of warnings on control processes and PM accuracy for these and other PM theoretical explanations are considered in more depth in the General discussion.

\section{Experiment 1}

Participants completed an ongoing lexical decision task with the PM task of responding to letter strings containing the syllable "tor." In the standard PM condition, all stimuli in both the control and PM blocks were colored green. In the context PM condition, participants were told that PM targets could only appear on red trials (PM-relevant context) and not on green trials (PM-irrelevant context). A unique feature of Experiment 1 was that PM-relevant trials were presented in sets of four, and PM targets could appear on either the first, second, or third trial in the set. We predicted that the context condition would have higher PM accuracy compared to the standard condition, but only for PM targets presented on the second or third trial of PM-relevant contexts. When PM targets are presented on the first trial of a PM-relevant set, participants in the context condition will have received no warning that they were approaching a PM-relevant context and PM control processes may not be sufficiently engaged. Participants in the context condition may also show reduced costs on PM-irrelevant trials, and/or increased costs on PMrelevant trials, compared to participants in the standard condition.

The third condition also uniquely builds upon prior studies by examining the effectiveness of warning trials presented prior to the PM-relevant context. For the warned + context condition, letter strings were presented in green, red, or yellow, and participants were told that PM targets could only appear on PM-relevant trials (red) and not on PM-irrelevant trials (green). Participants were further instructed that four warning trials (yellow) would always precede each set of four PM-relevant trials. We predicted that the warned + context condition would have higher PM accuracy compared to the standard condition for all PM targets, regardless of their trial position in a PM-relevant trial set, because the yellow trials should provide sufficient warning of upcoming PM-relevant contexts, thereby allowing participants to engage PM control processes prior to the potential PM target presentation.

\section{Method}

Participants (all experiments) Undergraduate students from the University of Western Australia participated in exchange for course credit and were randomly assigned to conditions. Five participants in Experiment 1 and three in Experiment 3 were excluded and replaced for not responding correctly to any of the PM targets. ${ }^{1}$ There were 48 participants in each condition across Experiments 1-3. There was sufficient power $(>.80)$ to detect a medium between-subjects effect of condition $(f=.25, \alpha=.05)$ in our PM accuracy ANOVAs for Experiments 1, 2, and 3 (power $=.91, .84$, and .96, respectively). The use of a medium effect size for the power calculations is in line with the studies included in Table 1, where those with significant effects of context most often reported medium effect sizes.

Design Participants in all conditions completed the same PM task of responding to the target syllable. Table 2 provides an overview of the design. In Experiment 1 participants were assigned to one of three conditions: a standard (no context) condition, a context condition where participants were instructed that PM targets would only appear on red trials, and a warned + context condition, where in addition to the context instructions participants were further instructed that yellow trials would always precede red trials.

Stimuli A pool of 220 high frequency (HF) words (150 occurrences per million) and 220 low frequency (LF) words (three

\footnotetext{
${ }^{1}$ The pattern of results reported is unchanged by the inclusion of these participants.
} 
Table 2 Participant descriptive statistics (mean age in years and gender) and design overview for each experiment

\begin{tabular}{llllll}
\hline Experiment & Age, $y$ & Gender & Condition & Ongoing task trial colors & Fixation colors \\
\hline $\mathbf{1}$ & 21.2 & $\mathrm{M}=48$ & 1. Standard & Green & N/A \\
& & $\mathrm{F}=96$ & 2. Context & Green, red & N/A \\
& & & 3. Warned + Context & Green, yellow, red & Green \\
$\mathbf{3}$ & 22.1 & $\mathrm{M}=35$ & 1. Standard & Green & Green, red \\
& & $\mathrm{F}=61$ & 2. Warned + Context & Green, red & Green, red \\
& & $\mathrm{M}=65$ & 1. Standard & Green & White \\
& & & 2. Standard (color-change) & Green, red & Green, red \\
\hline
\end{tabular}

In Experiments 2 and 3, each set of four trials was preceded by a rectangle fixation point that matched the color of upcoming trials (with the exception of the context condition in Experiment 3)

Note: In all experiments, 48 participants were assigned to each condition, after excluding outliers as described in text. In all context conditions, participants were instructed that the PM targets would only appear on red trials, making the red trials relevant to the PM task and making the green trials irrelevant to the PM task in these conditions. Color had no significance in the standard conditions

occurrences per million) were randomly selected from the 1994 issues of the Sydney Morning Herald word database (Dennis, 1995). Of these, $110 \mathrm{HF}$ words and $110 \mathrm{LF}$ words were used as word stimuli and the remainder were converted to non-words by replacing every vowel in each word with a randomly chosen alternate vowel (e.g., chemist to chamust). These stimuli were previously used by Heathcote et al. (2015). Two lists were created, with each list containing 220 items in total (55 HF words, $55 \mathrm{LF}$ words, and 110 non-words). Participants performed a control block (lexical decision only) followed by a PM block (lexical decision and PM). The assignments of condition and list were counterbalanced and the order of presentation of words and non-words within each list was random, with the exception of the presentation of PM targets. In the PM block, one target was presented within each of the following trial sequences: 10-19, 30-44, 55-69, 80-94, 105-119, 130-144,155-169, 180-194, and 205-214. Letter strings on PM target trials included the syllable "tor." PM targets were embedded three times in HF words (history, story, senator), three times in LF words (tutorial, ancestor, tortoise), and three times in non-words (torpun, cintor, extoruar). Trials were presented in colored text on a black background and the color of the letter strings varied as a function of condition.

Figure 1 provides a graphical representation of the task stimuli and how trial color differed between conditions. In the standard condition, all trials in the control and PM blocks were colored green, and thus color had no significance. In the context condition, 184 trials were green and 36 were red in both the control and PM blocks. During the control block color had no significance, but before the PM block participants in the context condition were told that PM targets could only appear on red trials (PM-relevant context) and not on green trials (PM-irrelevant context). PM-relevant trials were always presented in sets of four trials. A PM target was presented in either the first, second, or third trial position in the set. That is, targets were never presented in the fourth trial position, however, participants were not made aware of this. PM targets were distributed equally across trial positions, with three targets presented in first, second, and third position respectively. The assignment of these PM targets to trial position was randomized (without replacement) for each participant and then yoked across conditions.

For the warned + context condition, 148 trials were green, 36 were red, and 36 were yellow in both the control and PM blocks. During the control block color had no significance. Before the PM block the warned + context condition were

\begin{tabular}{|cccccc|}
$\begin{array}{c}\text { Trial } \\
\text { Number }\end{array}$ & Trial & $\begin{array}{c}\text { Standard } \\
\text { condition } \\
\text { color }\end{array}$ & $\begin{array}{c}\text { Context } \\
\text { condition } \\
\text { color }\end{array}$ & $\begin{array}{c}\text { Warn }+ \\
\text { Context } \\
\text { condition } \\
\text { color }\end{array}$ & $\begin{array}{c}\text { Correct } \\
\text { Response }\end{array}$ \\
\hline 8 & crook & green & green & green & word \\
9 & scabu & green & green & green & non-word \\
10 & sidu & green & green & green & non-word \\
11 & skull & green & green & green & word \\
\hline 12 & ecriss & green & green & yellow & non-word \\
13 & babbung & green & green & yellow & non-word \\
14 & book & green & green & yellow & word \\
15 & forego & green & green & yellow & word \\
\hline 16 & torpun & green & red & red & PM target \\
17 & dirr & green & red & red & non-word \\
18 & disunity & green & red & red & word \\
19 & lobe & green & red & red & word \\
\hline$\ldots$ & $\ldots$ & $\ldots$ & $\ldots$ & $\ldots$ & $\ldots$ \\
\hline
\end{tabular}

Fig. 1 Diagram showing a sample trial sequence for the standard, context, and warned + context conditions in Experiment 1. Trials were displayed in sets of four. For the context and warned + context conditions, color indicated whether a trial was PM-irrelevant (green) or PM-relevant context (red). For the warned + context condition, yellow trials provided a warning that the relevant context was to follow. In this example, the PM target is presented in the first position of the PM-relevant context 
told that PM targets could only appear on red trials and not on green trials or yellow trials. Participants were told that four yellow trials were provided to warn that a set of four red trials was to follow immediately and that PM targets could not appear on either warning or PM-irrelevant trials.

Procedure For the lexical decision task, participants decided if letter strings were English words or non-words and pressed the "F" key for a word or the "J" key for a non-word. Participants were told to make lexical decisions as quickly and accurately as possible. On each trial a 250 -ms blank (black) screen was followed by a colored letter string, which remained on the screen until the participant responded. Participants completed 32 practice lexical decision trials with feedback on the accuracy and speed of their response for each trial. Participants then worked on a Sudoku puzzle as a distracter task for $3 \mathrm{~min}$ before completing the control block of 220 trials. During the control and PM blocks there were two types of feedback after a response was made: if the participant made an incorrect lexical decision then the word "incorrect" was presented for $1,000 \mathrm{~ms}$, otherwise if the participant made a correct lexical decision then a blank screen was displayed for $1,000 \mathrm{~ms}$. There was no feedback provided regarding speed of response. Accuracy feedback was also not provided on PM target trials (i.e., the "incorrect" display was never presented on target trials).

Following the control block participants received additional instructions to press the "F1" key instead of the "F" or "J" key when presented with a letter string containing the syllable "tor." Participants in the standard condition received no information as to when PM targets could appear. Participants in the context and the warned + context conditions were provided with additional instructions regarding the significance of color, as described above. The full PM and context instructions for each condition in all experiments can be found in Appendix A. Participants then filled in a short questionnaire which confirmed their understanding of the PM task and what the trial colors indicated. Participants who did not answer the questionnaire correctly had the task re-explained before proceeding. Three minutes of the Suduko distracter task preceded the PM block.

\section{Results}

Data preparation For ongoing task analyses in the control block, we excluded the first two trials, trials with a RT of less than $300 \mathrm{~ms}$, and RT outliers (more than $2.5 S D$ above the individual's mean) for each trial color (Marsh, Hicks, \& Cook, 2006; Ratcliff, 1979). A total of $2.9 \%$ control block and 3.3\% PM block trials were removed prior to final averaging. In the PM block we additionally excluded PM target trials and PM false alarms. We corrected for family-wise error rate by reporting Bonferroni adjusted $p$ values (i.e., multiplying each $p$ value by the number of comparisons made for the specific analysis being followed up).

PM performance PM responses were scored as correct if they were made instead of the ongoing task response on PM target trials (pressing " $\mathrm{F} 1$ " on trials containing "tor"). ${ }^{2} \mathrm{~A} 3$ (position: first, second, third) $\times 3$ (condition: standard, cued, warned + context) mixed ANOVA was conducted on the proportion of correct PM responses (PM accuracy), where condition was the between-subjects factor and position was the within-subjects factor (Fig. 2). The significant main effects of position, $F(2,282)=9.76, p<.001, \eta_{p}{ }^{2}=.07$, and condition, $F(2,141)$ $=10.3, p<.001, \eta_{p}^{2}=.13$, were qualified by a significant interaction, $F(4,282)=3.54, p=.008, \eta_{p}^{2}=.05$.

When the target was presented in the first trial position, the context, $t<1$, and warned + context conditions did not differ from the standard condition, $t(94)=1.10, p=.82$. When the target was presented in the second trial position, $\mathrm{PM}$ accuracy was greater for both the context, $t(94)=3.86, p<.001, d=.79$, and the warned + context, $t(94)=4.19, p<.001, d=.86$, conditions compared to the standard condition. When the target was presented in the third position, PM accuracy was greater for both the context, $t(94)=4.53, p<.001, d=.93$, and the warned + context, $t(94)=3.50, p=.003, d=.72$, conditions compared to the standard condition. There was no difference between the context and the warned + context conditions at any of the three positions, all $t s<1$. In short, the context and the warned + context conditions had better PM accuracy than the standard condition when the PM target appeared on either the second or third trials of the PM-relevant context, but not when the target appeared on the first trial of the PM-relevant context.

PM false alarms The number of PM false alarms (pressing "F1" on trials not containing "tor") did not differ between the three conditions, $F<1$, and the average number of false alarms made per participant was less than one $(M=.42, S D$ $=.78$ ). An average number of .09 false alarms occurred on the trial immediately following a PM target. The pattern of significant results reported for PM accuracy in Experiments 1-3 was not changed if PM responses on the trial immediately following a PM target were treated as being correct.

Ongoing task performance on PM-irrelevant trials Although this study focuses primarily on the effect of context and warning on PM accuracy, we also analyzed ongoing task performance as this has commonly been the focus of much of the prior work on context and PM (see Smith \& Skinner, 2019, for

\footnotetext{
${ }^{2}$ Key-presses were not recorded during the inter-trial interval. Therefore, any attempts to press "F1" after an initial word/non-word response ("F" or "J") were not captured. We have no reason to expect that there would be any differences between conditions if these had been recorded and included in the PM accuracy data analysis.
} 


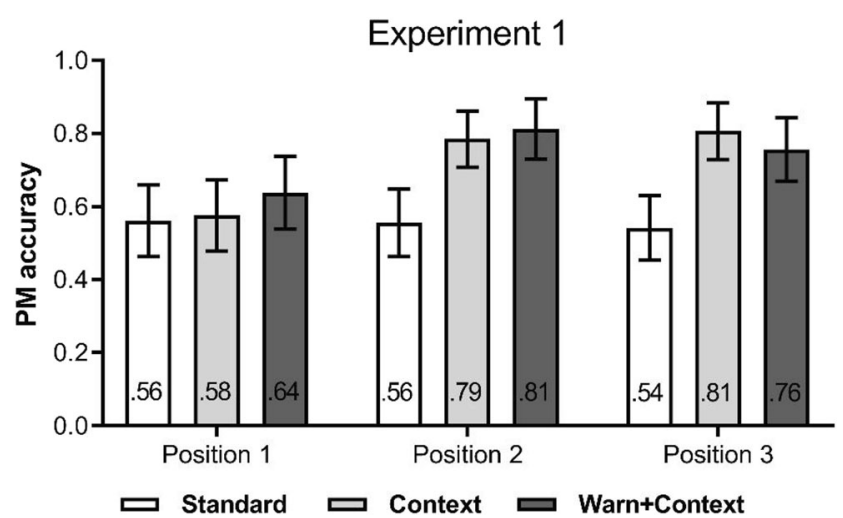

Fig. 2 Proportion correct prospective memory responses at each target position in Experiment 1. Errors bars represent $95 \%$ between-subjects confidence intervals

review). For conciseness, we present a summary of the primary findings regarding the effects of context and warning on performance on the PM-irrelevant trials below. ${ }^{3}$ For readers who would like to review the full analysis of ongoing task performance, including the analysis for warning and relevant trials, see Appendix B.

Regarding ongoing task accuracy on PM-irrelevant (green) trials, the warned + context condition showed evidence of decreased costs to ongoing task accuracy (the difference in accuracy between the control block and the PM block) relative to the standard condition, $t(94)=2.48, p=.045, d=.51$. Regarding ongoing task RTs, the context condition showed a decrease in RT costs on PM-irrelevant (green) trials (the difference in correct RT between the control block and the PM block) relative to the standard condition, $t(94)=4.26, p$ $<.001, d=.87$. There was a similar trend for the warned + context condition ongoing task RTs relative to the standard condition, $t(94)=2.23, p=.084, d=.45$, but this was not significant. Ongoing task RTs for the context and warned + context conditions did not differ, $t(94)=1.37, p=.53$. Overall, the ongoing task performance data indicates that context can lead to more efficient PM control processes during PMirrelevant trials, replicating a number of prior studies (see Smith \& Skinner, 2019, for review).

\section{Discussion}

Experiment 1 demonstrates reduced costs in PM-irrelevant contexts for participants provided contextual information in the context condition (marginal for warned + context condition) when compared to the standard condition, reflecting more efficient use of PM control processes. As predicted, the PM performance benefit for the context condition (without

\footnotetext{
${ }^{3}$ Note that because the control block always preceded the PM block these are not absolute measures of costs due to possible fatigue/practice effects, but the difference scores nonetheless allow for legitimate comparisons between the conditions and trial type regarding the effect of having a PM task demand on ongoing task performance.
}

warning) only occurred for PM targets that were presented on the second or third trial of PM-relevant contexts, and not on the first trial. This is likely because when PM targets were presented on the first trial of PM-relevant contexts, participants in the context condition had no warning that they were approaching a PM-relevant context.

Contrary to our expectations, there was no benefit to PM accuracy for targets that were presented in the first trial position when participants were warned four trials in advance of PM-relevant contexts. This is surprising, because the costs observed for warning trials (see Appendix B), relative to the context condition indicated that participants in the warned + context condition understood the relevance of the yellow trials and slowed their ongoing task responding in anticipation of an upcoming PM-relevant context. It is unclear then why the provision of a warning four trials in advance did not allow participants to adequately prepare for the possible presentation of a target in the first position of the relevant context, a point we explore in more detail in the General discussion.

\section{Experiment 2}

Experiment 1 demonstrated that a temporal proximity warning in the form of four yellow warning trials does not benefit PM performance on the first trial of PM-relevant contexts. The goal of Experiment 2 was to determine whether a different warning, one that still provides information about the temporal proximity of PM-relevant contexts, can improve PM performance to targets which appear in the first trial position.

The warning trials in Experiment 1 were embedded in the features of the ongoing task stimuli (color of the stimuli). In contrast, participants in the warned + context condition in Experiment 2 were instead presented with a colored fixation rectangle which appeared at the beginning of every set of four trials to signal the upcoming trial context. This new contextual warning is separate from the ongoing task letter string stimuli and thus serves solely as an indicator of whether an upcoming set of trials is relevant to the PM task. We suspected that this more separate contextual cue would increase the probability that PM control processses would be sufficiently engaged on the first trial of relevant contexts, thereby increasing the probability of correctly responding to a target event presented in the first trial position as well as all subsequent positions during PM-relevant contexts.

\section{Method}

Design This experiment included two conditions (see Table 2). The standard condition matched that of Experiment 1 . The warned + context was given the same context instructions as in Experiment 1, but the warning was 
instead provided by the colored fixation rectangle preceding each set of four trials.

Stimuli and procedure Stimuli and procedures matched Experiment 1 with the following exceptions. All trials in the control and PM blocks were presented in sets of four, where the first trial in each set was preceded by a colored fixation rectangle. For the standard condition, all trials and all fixation rectangles were shown in green in both the PM block and the control block. For the warned + context condition, the PMrelevant trials in the PM block were presented in red and all other trials were shown in green. The fixation rectangle color signaled the context of the upcoming four trials, where a red rectangle preceded each set of four PM-relevant trials and a green rectangle preceded each set of PM-irrelevant trials. Note that unlike Experiment 1, there were no yellow warning trials since the color of the fixation rectangle served as the warning mechanism instead. For the warned + context condition, the matched trials and fixation rectangles were also shown in red and green in the control block, although in this block color held no significance.

Each fixation rectangle was presented for $1 \mathrm{~s}$, and was followed by a $250-\mathrm{ms}$ blank screen before the first trial in the set of four trials was presented. Aside from this addition, trial timing and feedback was identical to that of Experiment 1. In the PM block, one PM target was presented within each of the following trial sequences: 9-20, 33-44, 57-68, 81-92, 105-116, 129-140, 153-164, 177-188, and 201-212. This sequence was slightly different from Experiment 1 to account for the four trial context groupings.

\section{Results and discussion}

Data preparation Using the same exclusion criteria as Experiment 1, a total of 3.0\% of the control block and 3.2\% of the PM block trials were removed.

Correct PM performance A 3 (position: first, second, third) $\times 2$ (condition: standard, warned + context) mixed ANOVA was conducted on PM accuracy (Fig. 3), with condition as the between-subjects factor and position as the within-subjects factor. There was no effect of position, $F<1$, and no interaction between position and condition, $F(2,188)=1.83, p=.16$. There was however an effect of condition, $F(1,94)=26.6, p$ $<.001, \eta_{p}{ }^{2}=.22$, where PM accuracy was significantly greater for the warned + context condition compared to the standard condition, $t(94)=5.16, p<.001, d=1.05$. PM accuracy was greater for the warned + context condition compared to the standard condition in the first, $t(94)=4.73, p<.001, d=.97$, second, $t(94)=3.96, p<.001, d=.81$, and third, $t(94)=2.51$, $p=.042, d=.51$, trial positions.

In summary, Experiment 2 replicated the beneficial effect of context on overall PM performance. Further, by using a

\section{Experiment 2}

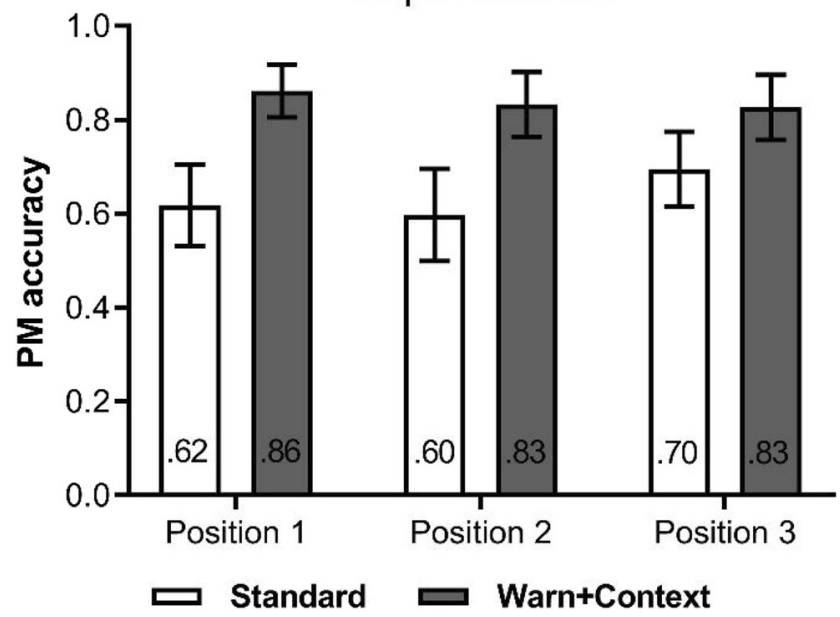

Fig. 3 Proportion correct prospective memory responses at each target position in Experiment 2. Errors bars represent 95\% between-subjects confidence intervals

warning signal that was separate from the ongoing task stimuli, the benefit of context to PM performance was also extended to include targets in the first trial position within the relevant context.

PM false alarms The number of PM false alarms did not differ between conditions, $t(94)=1.44, p=.15$, and the average number of false alarms made per participant was low $(M=$ $.41, S D=.92)$. An average number of 0.04 false alarms occurred on the trial immediately following a PM target.

Ongoing task performance on PM-irrelevant trials A detailed analysis of Experiment 2 ongoing task performance is provided in Appendix C. The conditions did not differ with respect to accuracy costs on PM-irrelevant trials, $t(94)=1.05, p=.59$. RT costs on PM-irrelevant trials were significantly reduced for the warned + context condition, $t(94)=4.95, p<.001, d=$ 1.01, compared to the standard condition, replicating Experiment 1 and showing that context can allow individuals to more selectively engage PM control processes.

\section{Experiment 3}

One potential concern with the design of Experiments 1 and 2 is that the standard condition did not include any equivalent color transitions (with trials always presented in green), whereas the context conditions included transitions from green to red (and additionally from yellow to red in Experiment 1). Although unlikely, it is possible that the color transitions themselves may have improved target detection by providing participants in the context conditions with a reminder of the PM task. Alternatively, the color transitions may have hindered PM target detection in the first position specifically 
due to difficulty adjusting to the color change, potentially accounting for the lack of benefit to PM accuracy in the first trial position for the context conditions compared to standard conditions in Experiment 1. Since both alternatives are plausible, a third experiment was conducted to address this issue.

The goals in Experiment 3 were to (a) replicate the finding from Experiment 2 that using a warning signal separate from the ongoing task stimuli can benefit PM performance for targets in the first trial position within the PM-relevant context, (b) replicate the finding from Experiment 1 that context without warning does not benefit PM performance for targets in the first trial position within the PM-relevant context, and (c) determine whether color transitions without context could account for the pattern of improved PM performance and ongoing task costs in Experiments 1 and 2. To address (a), we repeated the standard (green only) and warned + context conditions from Experiment 2. Addressing (b), a context condition was included, where the colored fixation rectangle was white so as to provide no information regarding the context of upcoming trials. Addressing (c), a standard (color-change) condition was included, where trials could be either red or green and the colored fixation rectangle matched the color of the upcoming trials. However, unlike the two context conditions, the presentation of PM targets for the standard (colorchange) condition was not restricted to red trials and participants were informed that color held no significance. This new standard condition allows us to determine the effect of color transitions on PM.

\section{Method}

Design Participants were randomly assigned to the four conditions (see Table 2).

Stimuli and procedure Stimuli and procedure matched Experiment 2 with the following exceptions. In the standard condition, trials and fixations were all one color (green). A new control condition containing color transitions was introduced, and is referred to as the standard (color-change) condition. Participants in this condition were informed that while color would vary between red and green, there was no significance to this change. Thus, there was no PM-relevant or PMirrelevant association with color in the standard (colorchange) condition. The standard (color-change) condition contained 36 red trials and 186 green trials, which preserved the red to green trial ratio from the context and warned + context conditions. In the standard (color-change) condition, three of the nine PM targets appeared on red trials in the first trial position. This allows for direct comparison between the context, warned + context, and standard (color-change) conditions, with all three conditions containing the same three PM targets appearing in red in the first trial position. The remaining six PM targets for the standard (color-change) condition appeared on green trials. In the standard (color-change) condition, the color of the fixation signaled the color of the upcoming four trials.

The context condition replicates Experiment 1, but with the addition of a white fixation rectangle. In the context condition, the PM-relevant trials in the PM block were presented in red, while all other trials were presented in green. All fixation rectangles were white, providing participants with no warning of the context of each subsequent set of four trials. The warned + context condition was identical to Experiment 2. Figure 4 provides a graphical representation of the task stimuli and how trial color differed between conditions in Experiment 3.

\section{Results and discussion}

Data preparation Using the same exclusion criteria as Experiments 1 and 2, a total of $2.7 \%$ of the control block and $3.2 \%$ of the PM block trials were removed.

Correct PM performance A 3 (position: first, second, third) $\times 4$ (condition: standard, standard (color-change), context, warned + context) mixed ANOVA was conducted on PM accuracy (Fig. 5), with condition as the between-subjects factor and position as the within-subjects factor. There was no effect of position, $F(2,376)=1.53, p=.22$, an effect of condition, $F(3,188)=16.4, p<.001, \eta_{p}{ }^{2}=.21$, and an interaction of position and condition, $F(6,376)=2.22, p=.041, \eta_{p}{ }^{2}=.03$.

When the target was presented in the first trial position, there was no difference in PM accuracy for the context

\begin{tabular}{|c|c|c|c|c|c|c|}
\hline $\begin{array}{c}\text { Trial } \\
\text { Number }\end{array}$ & Trial & $\begin{array}{c}\text { Standard } \\
\text { condition } \\
\text { color }\end{array}$ & $\begin{array}{l}\text { Standard } \\
\text { (color- } \\
\text { change) } \\
\text { condition } \\
\text { color }\end{array}$ & $\begin{array}{c}\text { Context } \\
\text { condition } \\
\text { color }\end{array}$ & $\begin{array}{c}\text { Warn }+ \\
\text { Context } \\
\text { condition } \\
\text { color }\end{array}$ & $\begin{array}{c}\text { Correct } \\
\text { Response }\end{array}$ \\
\hline$\square$ & [fixation] & [green] & [green] & [white] & [green] & 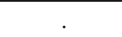 \\
\hline 8 & crook & green & green & green & green & word \\
\hline 9 & scabu & green & green & green & green & non-word \\
\hline 10 & sidu & green & green & green & green & non-word \\
\hline 11 & skull & green & green & green & green & word \\
\hline$\square$ & [fixation] & [green] & [red] & [white] & [green] & 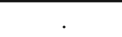 \\
\hline 12 & ecriss & green & red & green & green & non-word \\
\hline 13 & babbung & green & red & green & green & non-word \\
\hline 14 & book & green & red & green & green & word \\
\hline 15 & forego & green & red & green & green & word \\
\hline$\square$ & [fixation] & [green] & [green] & [white] & [red] & \\
\hline 16 & torpun & green & green & red & red & PM target \\
\hline 17 & dirr & green & green & red & red & non-word \\
\hline 18 & disunity & green & green & red & red & word \\
\hline 19 & lobe & green & green & red & red & word \\
\hline
\end{tabular}

Fig. 4 Diagram showing a sample trial sequence for the standard, standard (color-change), context, and warned + context conditions in Experiment 3. Trials were displayed in sets of four, with each set preceded by a colored fixation rectangle. The color of the fixation rectangle is in square brackets. The fixation correctly predicted the color of the upcoming four trials for all conditions except for the context condition, where the fixation was always white (no warning provided) 


\section{Experiment 3}

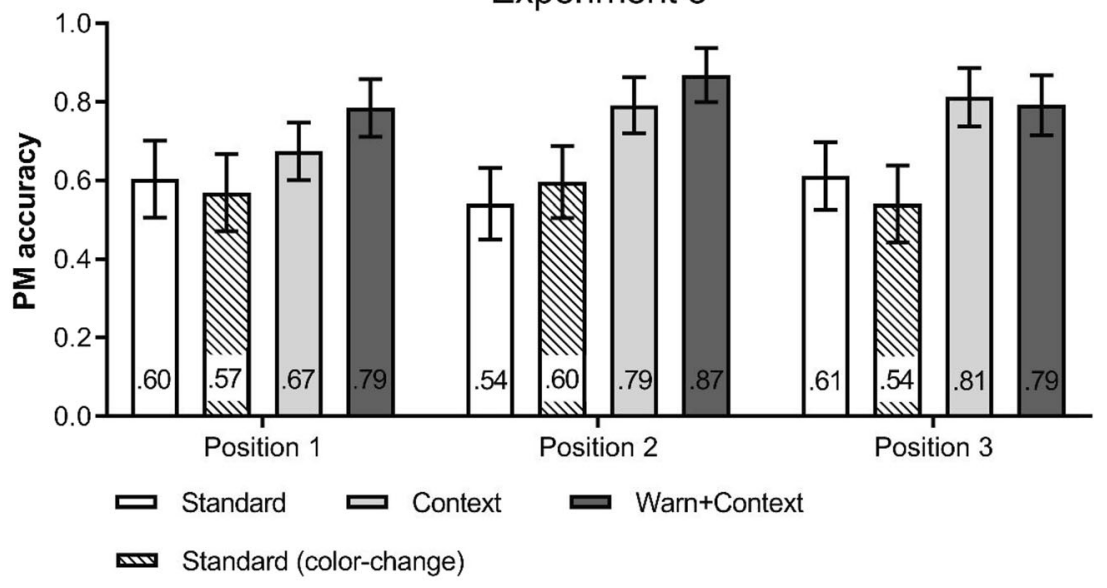

Fig. 5 Proportion correct prospective memory responses at each target position in Experiment 3. Errors bars represent $95 \%$ between-subjects confidence intervals

condition compared to the standard condition, $t(94)=1.15, p$ $=1.00$, and greater PM accuracy for the warned + context condition compared to the standard condition, $t(94)=2.99$, $p=.016, d=.61$. There was no difference between the context condition and the warned + context condition, $t(94)=2.15, p$ $=.14$. Importantly, there was no difference between the standard and standard (color-change) conditions, $t<1$, which shows that the color change neither benefitted nor impaired PM accuracy on color transition trials.

When the target was presented in the second trial position, PM accuracy was greater for both the context, $t(94)=4.37, p<$ $.001, d=.89$, and the warned + context, $t(94)=5.78, p<.001$, $d=1.18$, conditions compared to the standard condition. There was no difference between the context condition and the warned + context condition, $t(94)=1.56, p=.48$. There was no difference between the standard and standard (colorchange) conditions, $t<1$.

When the target was presented in the third trial position, PM accuracy was greater for both the context, $t(94)=3.57, p=$ $.004, d=.73$, and the warned + context, $t(94)=3.17, p=.008$, $d=.65$, conditions compared to the standard condition. There was no difference between the context and the warned + context conditions, $t<1$, and no difference between the standard and standard (color-change) conditions, $t(94)=1.08, p=1.00$.

In summary, Experiment 3 replicated key findings from Experiments 1 and 2. Context without warning improved PM accuracy for targets presented in the second and third trial positions, but not the first. The addition of a one second warning extended the PM accuracy benefit to include targets in the first trial position within a relevant context. Results also demonstrated that color transitions without associated context had no effect on PM accuracy.

PM false alarms The number of PM false alarms did not differ between conditions, $F<1$, and the average number of false alarms made per participant was low $(M=.56, S D=.97)$.
An average number of .13 false alarms occurred on the trial immediately following a PM target.

Ongoing task performance on PM-irrelevant trials A detailed analysis of Experiment 3 ongoing task performance is provided in Appendix D. Costs to ongoing task accuracy for PMirrelevant trials did not differ from the standard condition for either the context or the warned + context conditions, $t s<1$. Costs to accuracy did not differ between the warned + context condition and the context condition, $t<1$. Costs were significantly reduced for the standard (color-change) condition compared to the standard condition, $t(94)=4.09, p<.001, d=.84$.

Costs to ongoing task RTs for PM-irrelevant trials were reduced relative to the standard condition for both the context, $t(94)$ $=3.15, p=.008, d=.64$, and warned + context, $t(94)=7.37, p<$ $.001, d=1.51$, conditions, replicating Experiments 1 and 2 . There was no difference between the context condition and the warned + context condition, $t(94)=2.15, p=.14$. The standard (color-change) and standard conditions did not differ, $t<1$.

Overall, the ongoing task performance data replicates Experiment 1, by showing a reduced cost to the ongoing task during PM-irrelevant trials for both the context and warned + context conditions compared to the standard condition. The overall pattern across the three experiments remains relatively consistent and supports the conclusion that context can allow individuals to more selectively engage PM control processes. The addition of color transitions to the standard (colorchange) condition did not impact ongoing task RT costs, but unexpectedly it did reduce overall (irrespective of trial color) ongoing task accuracy costs.

\section{General discussion}

Our aim was to extend the literature by examining the extent to which warnings can facilitate the use of contextual 
information in a PM task that otherwise provides no information about the relative proximity to a PM-relevant context. Participants performed an ongoing lexical decision task while remembering to respond differently to PM targets (trials containing the syllable "tor"). Color was used to provide contextual information about whether a PM target could occur on a particular trial, and PM-relevant context trials were always presented in sets of four trials, with the PM target appearing in either the first, second, or third trial position of the set. To our knowledge this is the first experiment to examine the effects of context and warnings on PM accuracy as a function of the specific trial location of a target within the relevant context. Our findings also replicate numerous prior studies showing that context can reduce ongoing task costs for contexts in which the PM task is not relevant.

\section{Context effects on PM accuracy}

Table 1 provides a summary of the previous studies that investigated the effects of context on event-based PM performance. At first glance there appears to be a general lack of consistency in whether contextual support improves PM performance. However, closer examination shows that all studies reporting a benefit to PM accuracy were those which warned participants of the approach of PM-relevant contexts. The type of warning that was successful varied, and included proximity cues, designating relevant blocks of trials, and some trial-by-trial (within block) designs. It is worth noting however, that not all warning manipulations were successful (Ball \& Bugg, 2018b; Bugg \& Ball, 2017; Cona et al., 2015; Lourenço \& Maylor, 2014).

Another commonality of studies where a significant increase or trend towards PM accuracy improvement occurred was that PM performance in the no context condition (equivalent to our standard condition) was typically well below maximal levels. All the comparisons in Table 1 showing an effect of context included no context conditions with PM performance that was well below ceiling. In contrast, for the comparisons in which an effect of context was not demonstrated, performance in the no context condition tended to be very high, with less than one target missed on average. Thus, previous failures to find a benefit of context on PM performance could be partially attributable to a lack of sufficient range for detecting these effects. The current findings, combined with the pattern shown in Table 1, demonstrate that context does benefit PM performance when the PM task is sufficiently challenging.

\section{Context and warnings}

The current experiments have extended the investigation of how context benefits PM performance to consider how context and warnings can affect PM performance as a function of target location within the PM-relevant context. In all three experiments, providing participants with context information improved PM accuracy compared to the standard condition for PM targets appearing later in the target sequence (PMrelevant trial set positions 2 and 3 ). In contrast, contextual information without a warning did not improve PM accuracy for PM targets in the first position. In Experiments 1-3, the standard condition showed levels of PM performance well below ceiling and above floor, thus a restricted range of performance cannot explain the failure to show a benefit to the context conditions for the PM target in the first position.

In Experiment 1, participants were warned four trials in advance of PM-relevant contexts. These Experiment 1 warning trials were embedded in the features of the ongoing task stimuli (the color of the stimuli) and resulted in no benefit to PM accuracy for targets presented in the first trial position. In contrast, for Experiments 2 and 3, accuracy on the first target trial was improved when preceded by a 1-s pre-trial contextually diagnostic fixation which signaled the upcoming trial context. This fixation was separate from the ongoing task stimuli and served solely as an indicator of whether an upcoming set of trials was relevant to the PM task or not. Our results suggest that a brief, but separate, contextual cue was more successful at increasing the probability of correctly responding to targets presented in the first trial position (as well as all subsequent positions during PM-relevant contexts) than the longer embedded warning used in Experiment 1.

Alternatively, it may not be the features of the cue that determined efficacy, but that participants rapidly forgot the change in context (or the significance of the color change) over the four warning trials in Experiment 1. For the warned + context condition, in Experiment 1 the onset of the contextual warning was four trials before the PM-relevant context, while in Experiments 2 and 3 the warning was presented immediately prior to commencement of the PM-relevant context. It is therefore possible that on some occasions in Experiment 1 participants realized the relevance of the first warning trial, but did not keep that information in mind over the entire four warning trial set. In line with this, research examining the delayed execution of retrieved PM intentions has shown evidence of forgetting over quite brief delays (as little as 5-10 s; see Einstein, McDaniel, Manzi, Cochran, \& Baker, 2000; Einstein, McDaniel, Williford, Pagan, \& Dismukes, 2003). Dewitt, Hicks, Ball, and Knight (2012) also found that a priming cue presented three trials prior to a PM target improved detection accuracy relative to no cue, but a cue presented six trials prior did not. Future studies may therefore wish to explore whether single warning trials presented immediately prior to the first potential PM target may be effective using our Experiment 1 design.

\section{Theoretical explanations}

Taken together, the differences in methodology between Experiment 1 and Experiments 2 and 3 points to possible 
theoretical explanations for the difference in PM performance. The PAM theory proposes that we make decisions about which intentions are relevant in an upcoming context at points of transition (Smith, 2008). Smith et al. (2017) provide evidence for such decision processes at transition points when the ongoing task stimuli provided familiar spatial information, and Smith and Loft (2014) provided evidence that such decision processes are occurring when participants transition between blocks of the ongoing task demarcated by the type of stimuli in a given block. In Experiment 1, the color of the ongoing task stimuli also indicated whether the PM task was relevant on that trial. Thus, it is possible that when the first target position in the PM-relevant context is not preceded by the fixation indicator, participants were only just initiating preparatory attentional processes during the first position trial, and that either these processes were not sufficiently engaged while the stimulus was present or the decision processes themselves interfered with performance of the PM task. Presenting the fixation prior to the relevant context sequence, as in the warned + context condition in Experiments 2 and 3, may have initiated these processes sooner, allowing for completion of the decision processes before the target stimulus was presented or otherwise reduced interference between the decision mechanism and processes related to the PM task. Although Experiment 1 included the warning trials condition, these warning trials could also be seen as a non-relevant block, and while ongoing task RTs did increase in these trials, this does not mean that the transition to the next stimulus type (the PM-relevant set) would not also require the engagement of the $\mathrm{PM}$ decision processes again.

The DMPV proposes that when strategic monitoring is not engaged prior to encountering a target event, the retrieval of the intention when the target is encountered is probabilistic. This could explain lower performance on the targets appearing on the first red trial; however, RTs on the warning trials in Experiment 1 indicate that monitoring was engaged. Furthermore, it is unclear how DMPV would explain the differential effects of context across the experiments on performance for targets in the first position. However, if one assumes that there are different levels of strategic monitoring required and the second level is not engaged until after the first red trial appears in the context (without warning) conditions in Experiments 1-3, but is engaged by the red fixation stimulus prior to the first target position in the context with warning condition in Experiments 2 and 3, the findings can be accommodated by an explanation that combines the DMPV and a twoprocess monitoring model such as that proposed by Guynn (2003), or the Ball et al. (2020) concept of strategic engagement of monitoring in response to context, where approaching a relevant context triggers proactive reengagement of monitoring, and reactive engagement of monitoring occurs once in the relevant context.
Delay theory assumes that increasing ongoing task response thresholds allow more time for PM responses to reach a decision threshold, and are therefore functional to PM performance. Similar to the aforementioned PAM theory's interpretation, presenting the fixation prior to the target relevant context sequence in the context with warning condition in Experiments 2 and 3 may have facilitated the transition of ongoing task response threshold adjustment between PMrelevant and PM-irrelevant trials. However, as noted by Heathcote et al., they "presented a theory and model of ongoing-task performance and not of PM performance" that does not currently "posit the specific mechanisms responsible for PM performance" (p. 404).

Strickland, Loft, Remington, and Heathcote (2018) recently extended the Heathcote et al. (2015) delay theory to computationally model both the ongoing task and PM response (Prospective Memory Decision Control; PMDC). They reported that in addition to the control of ongoing task thresholds, individuals also control the threshold required to make PM responses (proactive control), and the relative rate at which evidence is accumulated for PM and ongoing task responses on PM target trials (reactive control). This suggests that both proactive control over PM responses and reactive control determine PM accuracy, and far more so than elevated ongoing task response thresholds (also see Strickland, Loft, \& Heathcote, 2020). The PMDC model accurately accounts for benchmark PM effects such as target focality and PM importance, and it would be useful to examine how proactive and reactive control change in response to the provision of $\mathrm{PM}$ context. This would, however, require many more experimental trials than were included in the current study.

Finally, recent work by Rummel, Smeekens, and Kane (2017) provides an alternative view of the current PM accuracy findings. Rummel et al. provide evidence suggesting that individuals can reduce task-unrelated thoughts to improve PM. The context warning provided by the red fixation may have allowed participants to reduce their task-unrelated thoughts at the first trial position in Experiments 2 and 3, and thus improve their PM accuracy. Future research using Rummel et al.'s approach to investigating mind wandering combined with manipulations of context may provide more direct evidence that context supports the avoidance of mind wandering in service of improved PM performance.

\section{Summary}

Providing contextual support improved PM performance overall and specifically for targets occurring on the second and third trial positions in the PM-relevant context. By using warning stimuli that separate from the ongoing task stimuli, the benefits of context on PM performance were also found for targets in the first trial position. Providing context resulted 
in a more efficient use of PM control processes in all experiments, even when the relative temporal proximity of the PMrelevant context could not be determined in advance, and the same beneficial pattern for control processes was maintained when participants were given warnings that the PM-relevant context was approaching. The current findings point to potential mechanisms of the effects of context on control processes to explain the effects of context on PM performance. Future research is needed to determine exactly which control processes are implicated in the use of context to support performance in a PM task.

Acknowledgement This research was supported by Discovery Grant DP12010311 from the Australian Research Council awarded to Loft and Smith.

\section{Appendix A - Prospective Memory Task and Context Instructions}

\section{All experiments and conditions}

PM task instructions "In addition to the lexical decision task, we also have an interest in your ability to remember to perform actions in the future. In the next block of lexical decision trials, when you see words or non-words that have the syllable "tor" in them, please try to remember to press the "F1" key instead of the " $F$ " or "J" key. For example, if you saw the word 'torso' you would press the "F1" key instead of the " $F$ " key. As another example, if you saw the non-word "stotoro,"c you would press the "F1" key instead of the "J" key."

\section{Experiment 1: Context instructions}

Standard condition "The words in this next block will be colored green, and words containing "tor" can appear on any trial. To summarize, in the next block of lexical decision trials, when you see words or non-words that have the syllable "tor" in them, please try to remember to press the "F1" key instead of the "F" or "J" key. The color of the words does not matter."

Context condition "To help make your task easier, the words in this next block will be either colored green or red. When a word is colored green it will not contain the "tor" syllable. When a word is colored red it might contain the "tor" syllable. Red colored words will be presented in blocks of four trials in a row, and there will be several blocks of red trials presented throughout this next task. To summarize, in the next block of lexical decision trials, when you see words or non-words that have the syllable "tor" in them, please try to remember to press the "F1" key instead of the "F" or "J" key. Words with the syllable "tor" in them can only occur on trials where the word is colored red."

Warned + context condition "To help make your task easier, the words in this next block will be either colored green, yellow, or red. When a word is colored green it will not contain the "tor" syllable. When a word is colored red it might contain the "tor" syllable. When a word is colored yellow it will not contain the "tor" syllable, but the color lets you know that there will be a block of red trials immediately after it. Red- and yellow-colored words are presented in blocks of four trials in a row. Four yellow trials will always come before four red trials. There will be several blocks of yellow followed by red trials presented throughout this next task. To summarize, in the next block of lexical decision trials, when you see words or non-words that have the syllable "tor" in them, please try to remember to press the "F1" key instead of the "F" or "J" key. Words with the syllable "tor" in them can only occur on trials where the word is colored red, and yellow trials will warn you that a block of red trials will follow."

\section{Experiment 2 context instructions}

Standard condition "The words in this next block will be colored green, and words containing "tor" can appear on any trial. Words are presented in groups of four, with a green rectangle being presented at the beginning of each group. To summarize, in the next block of lexical decision trials, when you see words or non-words that have the syllable "tor" in them, please try to remember to press the "F1" key instead of the "F" or "J" key. The color of the words does not matter. Words are presented in groups of four trials with a green rectangle at the beginning of each group."

Warned + context condition "To help make your task easier, the words in this next block will be either colored green or red. When a word is colored green it will not contain the "tor" syllable. When a word is colored red it might contain the "tor" syllable. Red colored words will be presented in groups of four trials in a row, and there will be several groups of red trials presented throughout this next task. You will know whether the upcoming group of four trials will contain red or green words by the color of the rectangle presented at the beginning of that group. To summarize, in the next block of lexical decision trials, when you see words or non-words that have the syllable "tor" in them, please try to remember to press the "F1" key instead of the "F" or "J" key. Words with the syllable "tor" in them can only occur on trials where the word is colored red. Words are presented in groups of four trials with either a green or a red rectangle at the beginning of each group." 


\section{Experiment 3 context instructions}

Standard condition "The words in this next block will be colored green or red, and words containing "tor" can appear on any trial. Words are presented in groups of four, with a green rectangle being presented at the beginning of each group. To summarize, in the next block of lexical decision trials, when you see words or non-words that have the syllable "tor" in them, please try to remember to press the "F1" key instead of the "F" or "J" key. The color of the words does not matter. Words are presented in groups of four trials with a green rectangle at the beginning of each group."

Standard (color-change) condition "The words in this next block will be colored green or red, and words containing "tor" can appear on any trial. Words are presented in groups of four, with a either a green or a red rectangle being presented at the beginning of each group. To summarize, in the next block of lexical decision trials, when you see words or nonwords that have the syllable "tor" in them, please try to remember to press the "F1" key instead of the "F" or "J" key. The color of the words does not matter. Words are presented in groups of four trials with either a green or a red rectangle at the beginning of each group.

Context condition "To help make your task easier, the words in this next block will be either colored green or red. When a word is colored green it will not contain the "tor" syllable. When a word is colored red it might contain the "tor" syllable. Red colored words will be presented in groups of four trials in a row, and there will be several groups of red trials presented throughout this next task. To summarize, in the next block of lexical decision trials, when you see words or non-words that have the syllable "tor" in them, please try to remember to press the "F1" key instead of the "F" or "J" key. Words with the syllable "tor" in them can only occur on trials where the word is colored red. Words are presented in groups of four trials with a white rectangle at the beginning of each group."

Warned + context condition "To help make your task easier, the words in this next block will be either colored green or red. When a word is colored green it will not contain the "tor" syllable. When a word is colored red it might contain the "tor" syllable. Red colored words will be presented in groups of four trials in a row, and there will be several groups of red trials presented throughout this next task. You will know whether the upcoming group of four trials will contain red or green words by the color of the rectangle presented at the beginning of that group. To summarize, in the next block of lexical decision trials, when you see words or non-words that have the syllable "tor" in them, please try to remember to press the "F1" key instead of the "F" or " $\mathrm{J}$ " key. Words with the syllable "tor" in them can only occur on trials where the word is colored red. Words are presented in groups of four trials with either a green or a red rectangle at the beginning of each group."

\section{Appendix B - Experiment 1: Analysis of ongoing task performance}

In each ongoing task analysis a 3 (condition: standard, context, warned + context) $\times 3$ (trial type: PM-irrelevant, warning, PM-relevant) mixed ANOVA was conducted, with condition a between-subjects factor and trial type a within-subjects factor. Note that since not all conditions included all the three different colored trials, in the analyses below we compare the trials that occurred at the same position in the trial sequence. For example, in the standard condition all trials were actually green, but here we separate them into PM-irrelevant (green), warning (yellow), and PM-relevant (red) trials based on the corresponding position of the warning and PM-relevant trials in the context and warned + context conditions. Where sphericity was violated a Greenhouse-Geisser correction was applied to the degrees of freedom. ANOVAs were followed up with Bonferroni-corrected $t$-tests where appropriate.

Control block accuracy and RT A $3 \times 3$ mixed ANOVA on control block accuracy (Table 3 ) revealed no effects of trial type, $F(1.7,245.7)=2.03, p=.14$, or condition, $F<1$, and no interaction between trial type and condition, $F<1$. Likewise, a $3 \times 3$ mixed ANOVA on control block RT (Table B2) revealed no effects of trial type, condition, and no interaction between trial type and condition, all $F_{S}<1$. The analyses confirm that trial type did not influence RT or accuracy in the control block when color held no significance to participants prior to receiving their condition specific PM instructions.

Costs to ongoing task accuracy and RT Table 3 presents the ongoing task accuracy costs; calculated as the difference in ongoing task accuracy between the control block and the PM block. Table 4 presents the ongoing task RT costs; calculated as the difference in ongoing task RT between the control block and the PM block. Note that because the control block always preceded the PM block these are not absolute measures of costs due to possible fatigue/practice effects with time, but the difference scores nonetheless allow for legitimate comparisons between the conditions and trial type regarding the effect of having a PM task demand on ongoing task performance.

A $3 \times 3$ mixed ANOVA on accuracy costs revealed no effect of trial type, $F<1$, and no interaction between trial type and condition, $F<1$. The main effect of condition on costs to ongoing task accuracy approached significance, $F(2,141)=$ $2.73, p=.069, \eta_{p}{ }^{2}=.04$, with participants in the warned + context condition showing a greater overall cost to ongoing task accuracy than participants in the standard condition, $t(94)$ $=2.48, p=.045, d=.51$. There was no accuracy cost 
Table 3 Experiment 1 ongoing task accuracy means (standard deviations in parentheses) for the control block, PM block, and the PM minus control block (accuracy costs). In the standard (no context) condition all trials are irrelevant (green), so the italicized warning (yellow) and relevant (red) means reflect the equivalent irrelevant trials (the same principle applies to warning trials in the context condition)

\begin{tabular}{|c|c|c|c|c|c|c|c|c|c|}
\hline & \multicolumn{3}{|c|}{ Control block } & \multicolumn{3}{|l|}{ PM block } & \multicolumn{3}{|c|}{ Accuracy costs } \\
\hline & Irrelevant & Warning & Relevant & Irrelevant & Warning & Relevant & Irrelevant & Warning & Relevant \\
\hline Standard & $.90(.05)$ & $.90(.08)$ & $.88(.06)$ & $.90(.05)$ & $.90(.07)$ & $.90(.08)$ & $.00(.03)$ & $.00(.07)$ & $.02(.07)$ \\
\hline Context & $.90(.04)$ & $.90(.06)$ & $.89(.08)$ & $.90(.04)$ & $.90(.07)$ & $.90(.07)$ & $.00(.03)$ & $.00(.08)$ & $.01(.08)$ \\
\hline Warn+Context & $.90(.04)$ & $.91(.06)$ & $.90(.06)$ & $.90(.04)$ & $.90(.07)$ & $.88(.08)$ & $.00(.03)$ & $-.01(.08)$ & $-.02(.08)$ \\
\hline
\end{tabular}

difference between the context and standard conditions, $t<1$, or the context and warned + context conditions, $t(94)=1.46, p$ $=.45$.

A $3 \times 3$ mixed ANOVA on RT costs revealed an effect of trial type, $F(1.3,178.9)=145.3, p<.001, \eta_{p}{ }^{2}=.51$, no effect of condition, $F(2,141)=1.41, p=.25$, and an interaction between trial type and condition, $F(2.5,178.9)=20.7, p<$ $.001, \eta_{p}{ }^{2}=.23$. Costs on PM-irrelevant (green) trials were significantly reduced for the context condition, $t(94)=4.26$, $p<.001, d=.87$, and marginally reduced for the warned + context condition, $t(94)=2.23, p=.084, d=.45$, compared to the standard condition. This suggests the context conditions benefited from the knowledge that the PM target would not appear on the PM-irrelevant trials. There was no difference between the context and the warned + context conditions on PM-irrelevant trials, $t(94)=1.37, p=.53$.

The costs on PM-relevant (red, or equivalent position) trials were significantly greater for both the context, $t(94)$ $=4.70, p<.001, d=.96$, and warned + context, $t(94)=$ $3.58, p=.003, d=.73$, conditions compared to the standard condition. This could indicate that both groups increased PM control processes in the relevant set of trials. However, these increased costs on PM-relevant trials could also partly reflect post-PM response output monitoring processes (Meier \& Rey-Mermet, 2012). There was no difference between the context and the warned + context conditions on PM-relevant trials, $t<1$.

The cost for warning (yellow, or equivalent position) trials showed a differentiation between the two context conditions, where the RTs for warning trials were longer in the warned + context than in the context condition, $t(94)=3.28, p=.001, d$ $=.67$, indicating that participants in the warned + context condition slowed their ongoing task responding during warning trials in anticipation of an upcoming relevant PM context ${ }^{4}$.

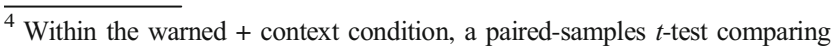
cost to irrelevant trials and cost to warning trials was conducted. The analysis revealed a significant difference between trial types, $t(47)=3.05, p=.004, d=$ .36 , where participants made slower correct lexical decisions on warning trials compared to irrelevant trials.
}

\section{Appendix C - Experiment 2: Analysis of ongoing task performance control block accuracy and RT}

A $2 \times 2$ mixed ANOVA on control block accuracy (Table 5) revealed no effect of trial type, $F<1$, and no interaction between trial type and condition, $F=1$. There was a main effect of condition, $F(1,94)=5.29, p=.024, \eta_{\mathrm{p}}{ }^{2}=.05$, where the standard condition was less accurate than the warned + context condition. A $2 \times 2$ mixed ANOVA on control block RT (Table C2) revealed no effect of trial type, $F<1$, or condition, $F<1$, but there was an interaction between trial type and condition, $F(1,94)=10.9, p=.001, \eta_{\mathrm{p}}{ }^{2}=.10$. This interaction was due to participants in the warned + context condition responding faster to the green trials compared to red trials during the control block, $t(47)=2.52, p=.030, d=.15$, whereas the standard condition responded marginally more slowly to green trials compared to red trials during the control block, $t(47)=2.14, p=.076, d=.13$. The difference in RT to green and "red" trials in the standard condition is effectively meaningless, since all standard trials were actually green (categorizing them as red simply indicates that they occurred at the same position in the trial sequence as red trials for the warned + context condition participants).

\section{Costs to ongoing task accuracy and RT}

A $2 \times 2$ mixed ANOVA on ongoing task accuracy costs (Table 5) revealed no effect of trial type, $F<1$, but an effect of condition, $F(1,94)=16.9, p<.001, \eta_{\mathrm{p}}{ }^{2}=.15$, and an interaction between trial type and condition, $F(1,94)=9.43$, $p=.003, \eta_{\mathrm{p}}{ }^{2}=.09$. During PM-irrelevant trials, there was no ongoing task accuracy cost difference between the two conditions, $t(94)=1.05, p=.59$. During PM-relevant trials, the warned + context condition had greater costs to ongoing task accuracy than the standard condition, $t(94)=3.88, p<.001, d$ $=.79$.

A $2 \times 2$ mixed ANOVA on RT costs (Table 6) revealed an effect of trial type, $F(1,94)=178.9, p<.001, \eta_{p}{ }^{2}=.66$, a marginal effect of condition, $F(1,94)=2.95, p=.089$, and an interaction between trial type and condition, $F(1,94)=$ 
Table 4 Experiment 1 RT means (and standard deviations) in milliseconds for the control block, PM block, and the PM minus control block (RT costs)

\begin{tabular}{|c|c|c|c|c|c|c|c|c|c|}
\hline & \multicolumn{3}{|c|}{ Control block } & \multicolumn{3}{|l|}{ PM block } & \multicolumn{3}{|l|}{ RT costs } \\
\hline & Irrelevant & Warning & Relevant & Irrelevant & Warning & Relevant & Irrelevant & Warning & Relevant \\
\hline Standard & $672(90)$ & $670(92)$ & $674(90)$ & $787(111)$ & 788 (127) & $848(160)$ & +115 (77) & $+118(95)$ & $+174(125)$ \\
\hline Context & $662(92)$ & $660(101)$ & $661(93)$ & 707 (136) & $699(134)$ & $1014(285)$ & $+45(84)$ & +39 (92) & $+353(233)$ \\
\hline Warn+Context & $681(120)$ & 690 (129) & $691(140)$ & $753(175)$ & 806 (193) & $1031(328)$ & +72 (109) & $+116(134)$ & +339 (296) \\
\hline
\end{tabular}

In the standard (no context) condition all trials are irrelevant (green), so the italicized warning (yellow) and relevant (red) means reflect the equivalent irrelevant trials as matched by trial number across conditions (the same principle applies to warning trials in the context condition)

24.4, $p<.001, \eta_{p}{ }^{2}=.21$. RT costs on PM-irrelevant trials were significantly reduced for the warned + context condition, $t(94)$ $=4.95, p<.001, d=1.01$, compared to the standard condition, replicating Experiment 1. RT costs on the PM-relevant trials did not differ between conditions, $t<1$.

Although RT costs on the PM-relevant trials did not differ between the warned + context and standard conditions, participants in the warned + context condition had greater costs to ongoing task accuracy than the standard condition during PMrelevant trials. Thus, the overall pattern across the two experiments is consistent, with the warned + context condition showing a reduced cost to the ongoing task during PMirrelevant trials and an increased cost during the PM-relevant trials. These results, along with Experiment 1, replicate prior studies showing that context can allow individuals to more selectivly engage PM control processes.

\section{Appendix D - Experiment 3: Analysis of ongoing task performance}

In each ongoing task analysis a 4 (condition: standard, standard (color-change), context, warned + context $) \times 2$ (trial type: PM-irrelevant, PM-relevant) mixed ANOVA was conducted, where condition was between-subjects and trial type was within-subjects. Ongoing task analyses for the standard and standard (color-change) conditions use the equivalent position trials to the context and warned + context conditions to facilitate comparison (e.g., in the standard condition where all trials are green, the equivalent position trials form the PM-relevant and PM-irrelevant trial types).

\section{Control block accuracy and RT}

A $4 \times 2$ mixed ANOVA on control block accuracy (Table 7) revealed no effect of trial type or condition, $F_{\mathbf{S}}<1$, and no interaction between trial type and condition, $F(3,188)=$ 1.34, $p=.26$. A $4 \times 2$ mixed ANOVA on control block RT (Table 8 ) revealed no effect of trial type or condition, $F \mathbf{S}<1$, and no interaction between trial type and condition, $F(3,188)$ $=1.61, p=.19$.

\section{Costs to ongoing task accuracy and RT}

A $4 \times 2$ mixed ANOVA on ongoing task accuracy costs (Table 7) revealed main effects of trial type, $F(1,188)=$ $14.7, p<.001, \eta_{\mathrm{p}}^{2}=.07$, and condition, $F(3,188)=13.2, p$ $<.001, \eta_{\mathrm{p}}^{2}=.17$, as well as a marginal interaction between trial type and condition, $F(3,188)=2.37, p=.072, \eta_{\mathrm{p}}^{2}=.04$.

During PM-irrelevant trials, there was no difference in costs to ongoing task accuracy between either the context condition, or the warned + context condition, compared to the standard condition, $t s<1$. There was no difference between the context and the warned + context conditions on PMirrelevant trials, $t<1$. Costs were significantly reduced for the standard (color-change) condition compared to the standard condition, $t(94)=4.09, p<.001, d=.84$.

Table 5 Experiment 2 ongoing task accuracy means (standard deviations in parentheses) for the control block, PM block, and the PM minus control block (accuracy costs)

\begin{tabular}{|c|c|c|c|c|c|c|}
\hline & \multicolumn{2}{|c|}{ Control block } & \multicolumn{2}{|l|}{ PM block } & \multicolumn{2}{|c|}{ Accuracy costs } \\
\hline & Irrelevant & Relevant & Irrelevant & Relevant & Irrelevant & Relevant \\
\hline Standard & $.91(.05)$ & $.90(.07)$ & $.91(.05)$ & $.92(.06)$ & $.00(.03)$ & $.02(.08)$ \\
\hline Warn+Context & $.92(.04)$ & $.93(.06)$ & $.92(.05)$ & $.89(.08)$ & $.00(.03)$ & $-.04(.07)$ \\
\hline
\end{tabular}

In the standard condition all trials are irrelevant (green), so the italicized relevant (red) means reflect the equivalent irrelevant trials 
Table 6 Experiment 2 RT means (and standard deviations) in milliseconds for the control block, PM block, and the PM minus control block (RT costs)

\begin{tabular}{|c|c|c|c|c|c|c|}
\hline & \multicolumn{2}{|c|}{ Control block } & \multicolumn{2}{|l|}{ PM block } & \multicolumn{2}{|l|}{ RT costs } \\
\hline & Irrelevant & Relevant & Irrelevant & Relevant & Irrelevant & Relevant \\
\hline Standard & 718 (109) & 704 (102) & 835 (118) & 912 (161) & 117 (64) & 208 (106) \\
\hline Warn+Context & $692(111)$ & $711(134)$ & $721(153)$ & $937(200)$ & $29(105)$ & $227(155)$ \\
\hline
\end{tabular}

In the standard condition all trials are irrelevant (green), so the italicized relevant (red) means reflect the equivalent irrelevant trials

Table 7 Experiment 3 ongoing task accuracy means (standard deviations in parentheses) for the control block, PM block, and the PM minus control block (accuracy costs)

\begin{tabular}{|c|c|c|c|c|c|c|}
\hline & \multicolumn{2}{|c|}{ Control block } & \multicolumn{2}{|l|}{ PM block } & \multicolumn{2}{|c|}{ Accuracy costs } \\
\hline & Irrelevant & Relevant & Irrelevant & Relevant & Irrelevant & Relevant \\
\hline Standard & $.90(.04)$ & $.91(.07)$ & $.91(.05)$ & $.89(.08)$ & $.00(.03)$ & $-.01(.08)$ \\
\hline Standard (color-change) & $.89(.05)$ & $.90(.07)$ & $.92(.04)$ & $.92(.06)$ & $.03(.03)$ & $.02(.07)$ \\
\hline Context & $.92(.04)$ & $.91(.07)$ & $.92(.05)$ & $.89(.08)$ & $.00(.03)$ & $-.02(.08)$ \\
\hline Warn+Context & $.90(.05)$ & $.91(.07)$ & $.90(.05)$ & $.87(.08)$ & $.00(.03)$ & $-.04(.07)$ \\
\hline
\end{tabular}

In the standard condition all trials are irrelevant (green), so the italicized relevant (red) means reflect the equivalent irrelevant trials. In the standard (colorchange) condition trials were either red or green, but there was no PM relevance associated with color

During PM-relevant trials, there was no difference in costs to ongoing task accuracy between either the context condition, $t<1$, or the warned + context condition, $t(94)=1.95, p=.22$, compared to the standard condition. There was no difference between the context and the warned + context conditions on PM-relevant trials, $t(94)=1.59, p=.46$. Costs were significantly reduced for the standard (color-change) condition compared to the standard condition, $t(94)=2.63, p=.040, d=.54$.

A $2 \times 4$ mixed ANOVA on RT costs (Table 8 ) revealed an effect of trial type, $F(1,188)=310.9, p<.001, \eta_{p}{ }^{2}=.62$, no effect of condition, $F(3,188)=1.55, p=.20$, and an interaction between trial type and condition, $F(3,188)=35.4, p<.001$, $\eta_{p}^{2}=.36$.

During PM-irrelevant trials, ongoing task RT costs were significantly reduced for both the context, $t(94)=3.15, p=$
$.008, d=.64$, and warned + context, $t(94)=7.37, p<.001, d=$ 1.51 , conditions compared to the standard condition, replicating Experiments 1 and 2. There was no difference between the context and the warned + context conditions on PM-irrelevant trials, $t(94)=2.15, p=.14$. There was no difference between the standard (color-change) and standard conditions on PMirrelevant trials, $t<1$.

The costs on PM-relevant trials were significantly greater for both the context, $t(94)=4.03, p<.001, d=.82$, and warned + context, $t(94)=2.80, p=.024, d=.57$, conditions compared to the standard condition, replicating Experiment 1. There was no difference between the context and the warned + context conditions, $t(94)=1.36, p=.71$, or between the standard (color-change) and standard conditions on PM-relevant trials, $t<1$.

Table 8 Experiment 3 RT means (and standard deviations) in milliseconds for the control block, PM block, and the PM minus control block (RT costs)

\begin{tabular}{|c|c|c|c|c|c|c|}
\hline & \multicolumn{2}{|c|}{ Control block } & \multicolumn{2}{|l|}{ PM block } & \multicolumn{2}{|l|}{ RT costs } \\
\hline & Irrelevant & Relevant & Irrelevant & Relevant & Irrelevant & Relevant \\
\hline Standard & $678(109)$ & $683(136)$ & 809 (152) & 874 (199) & $131(91)$ & $190(137)$ \\
\hline Standard (color-change) & $687(107)$ & $691(113)$ & 809 (128) & $894(169)$ & $123(86)$ & 204 (113) \\
\hline Context & $695(107)$ & $700(121)$ & $756(165)$ & $1032(254)$ & $62(124)$ & $332(201)$ \\
\hline Warn+Context & 686 (136) & $672(100)$ & 706 (146) & 951 (214) & $20(52)$ & $280(174)$ \\
\hline
\end{tabular}

In the standard condition all trials are irrelevant (green), so the italicized relevant (red) means reflect the equivalent irrelevant trials. In the standard (colorchange) condition trials were either red or green, but there was no PM relevance associated with color 


\section{References}

Ball, B. H., Brewer, G. A., Loft, S., \& Bowden, V. (2015). Uncovering continuous and transient monitoring profiles in event-based prospective memory. Psychonomic Bulletin \& Review, 22, 492-499. https://doi.org/10.3758/s13423-014-0700-8

Ball, B. H., \& Bugg, J. M. (2018a). Context cue focality influences strategic prospective memory monitoring. Psychonomic Bulletin \& Review, 25(4), 1405-1415.

Ball, B. H., \& Bugg, J. M. (2018b). Aging and the strategic use of context to control prospective memory monitoring. Psychology and Aging, 33(3), 527-544. https://doi.org/10.1037/pag0000247

Ball, B. H., Li, Y. P., \& Bugg, J. M. (2020). Aging and strategic prospective memory monitoring. Memory \& Cognition, 48, 370-389. https://doi.org/10.3758/s13421-019-00976-8

Bowden, V. K., Smith, R. E., \& Loft, S. (2017). Eye movements provide insights into the conscious use of context in prospective memory. Consciousness and Cognition, 52, 68-74. https://doi.org/10.1016/j. concog.2017.04.003

Brewer, G. A., \& Marsh, R. L. (2010). On the role of episodic future simulation in encoding of prospective memories. Cognitive Neuroscience, 1(2), 81-88. https://doi.org/10.1080/ 17588920903373960

Brewer, G. A., Marsh, R. L., Clark-Foos, A., Meeks, J. T., Cook, G. I., \& Hicks, J. L. (2011). A comparison of activity-based to event-based prospective memory. Applied Cognitive Psychology, 25(4), 632640. https://doi.org/10.1002/acp.1733

Bugg, J. M., \& Ball, B. H. (2017). The strategic control of prospective memory monitoring in response to complex and probabilistic contextual cues. Memory \& Cognition, 1-21. https://doi.org/10.3758/ s13421-017-0696-1

Cona, G., Arcara, G., Tarantion, V., \& Bisiacchi, P. S. (2015). Does predictability matter? Effects of cue predictability on neurocognitive mechanisms underlying prospective memory. Frontiers in Human Neuroscience, 9, 1-12. https://doi.org/10.3389/fnhum.2015.00188

Dennis, S. (1995). The Sydney Morning Herald word database. Noetica: Open Forum Retrieved from http://psy.uq.edu.au/CogPsych/ Noetica

Dewitt, M. R., Hicks, J. L., Ball, B. H., \& Knight, J. B. (2012). Encountering items previously paired with prospective memory target events can serve to reactivate intentions. Journal of Cognitive Psychology, 24(8), 981-990. https://doi.org/10.1080/20445911. 2012.727389

Einstein, G. O., \& McDaniel, M. A. (1990). Normal aging and prospective memory. Journal of Experimental Psychology: Learning, Memory, and Cognition, 16, 717-726. https://doi.org/10.1037/ 0278-7393.16.4.717

Einstein, G. O., McDaniel, M. A., Manzi, M., Cochran, B., \& Baker, M. (2000). Prospective memory and aging: forgetting intentions over short delays. Psychology and Aging, 12, 671-683. https://doi.org/ 10.1037/0882-7974.15.4.671

Einstein, G. O., McDaniel, M. A., Thomas, R., Mayfield, S., Shank, H., Morrisette, N., \& Breneiser, J. (2005). Multiple processes in prospective memory retrieval: factors determining monitoring versus spontaneous retrieval. Journal of Experimental Psychology: General, 134(3), 327-342. https://doi.org/10.1037/0096-3445.134. 3.327

Einstein, G. O., McDaniel, M. A., Williford, C. L., Pagan, J. L., \& Dismukes, R. K. (2003). Forgetting of intentions in demanding situations is rapid. Journal of Experimental Psychology: Applied, 9, 147-162. https://doi.org/10.1037/1076-898X.9.3.147

Guynn, M. J. (2003). A two-process model of strategic monitoring in event-based prospective memory: Activation/retrieval mode and checking. International Journal of Psychology, 38(4), 245-256. https://doi.org/10.1080/00207590344000178
Heathcote, A., Loft, S., \& Remington, R. W. (2015). Slow down and remember to remember! A delay theory of prospective memory costs. Psychological Review, 122(2), 376-410. https://doi.org/10. 1037/a0038952

Kominsky, T. K., \& Reese-Melancon, C. (2017). Effects of context expectation on prospective memory performance among older and younger adults. Memory, 25(1), 122-131. https://doi.org/10.1080/ 09658211.2015 .1131300

Kuhlmann, B. G., \& Rummel, J. (2014). Context-specific prospectivememory processing: Evidence for flexible attention allocation adjustments after intention encoding. Memory \& Cognition, 42(6), 943-949. https://doi.org/10.3758/s13421-014-0405-2

Kvavilashvili, L., \& Ellis, J. (1996). Varieties of intention: Some distinctions and classifications. Prospective memory: Theory and applications, 6, 183-207.

Loft, S., Finnerty, D., \& Remington, R. W. (2011). Using spatial context to support prospective memory in simulated air traffic control. Human Factors: The Journal of the Human Factors and Ergonomics Society, 53(6), 662-671. https://doi.org/10.1177/ 0018720811421783

Lourenço, J. S., \& Maylor, E. A. (2014). Is it relevant? Influence of trial manipulations of prospective memory context on task interference. Quarterly Journal of Experimental Psychology, 67(4), 687-702. https://doi.org/10.1080/17470218.2013.826257

Lourenço, J. S., White, K., \& Maylor, E. A. (2013). Target context specification can reduce costs in nonfocal prospective memory. Journal of Experimental Psychology: Learning, Memory, and Cognition, 39(6), 1757-1764. https://doi.org/10.1037/a0033702

Marsh, R., Hicks, J., \& Cook, G. (2006). Task interference from prospective memories covaries with contextual associations of fulfilling them. Memory \& Cognition, 34(5), 1037-1045. https://doi.org/10. 3758/BF03193250

Meier, B., \& Rey-Mermet, A. (2012). Beyond monitoring: After-effects of responding to prospective memory targets. Consciousness and Cognition, 21(4), 1644-1653.

Meier, B., Zimmermann, T. D., \& Perrig, W. J. (2006). Retrieval experience in prospective memory: Strategic monitoring and spontaneous retrieval. Memory, 14(7), 872-889. https://doi.org/10.1080/ 09658210600783774

Ratcliff, R. (1979). Group reaction time distributions and an analysis of distribution statistics. Psychological Bulletin, 86(3), 446-461. https://doi.org/10.1037/0033-2909.86.3.446

Rummel, J., Smeekens, B. A., \& Kane, M. J. (2017). Dealing With Prospective Memory Demands While Performing an Ongoing Task: Shared Processing, Increased On-Task Focus, or Both? Journal of Experimental Psychology: Learning, Memory, and Cognition, 43(7), 1047-1062. https://doi.org/10.1037/xlm0000359

Scullin, M. K., McDaniel, M. A., \& Shelton, J. T. (2013). The Dynamic Multiprocess Framework: Evidence from prospective memory with contextual variability. Cognitive Psychology, 67(1), 55-71. https:// doi.org/10.1016/j.cogpsych.2013.07.001

Smith, R. E. (2003). The cost of remembering to remember in eventbased prospective memory: investigating the capacity demands of delayed intention performance. Journal of Experimental Psychology: Learning, Memory, and Cognition, 29(3), 347-361. https://doi.org/10.1037/0278-7393.29.3.347

Smith, R. E. (2008). Connecting the past and the future: Attention, memory, and delayed intentions. In M. Kliegel, M. A. McDaniel, \& G. O. Einstein (Eds.), Prospective memory: Cognitive, neuroscience, developmental, and applied perspectives (pp. 27-50). Mahwah: Erlbaum.

Smith, R. E. (2010). What costs do reveal and moving beyond the cost debate: Reply to Einstein and McDaniel (2010). Journal of Experimental Psychology: Learning, Memory, and Cognition, 36(4), 1089-1095. https://doi.org/10.1037/a0019183 
Smith, R. E. (2017). Prospective memory in context. In B. H. Ross (Ed.), The Psychology of Learning and Motivation. New York: Academic Press.

Smith, R. E., Hunt, R. R., \& Murray, A. E. (2017). Prospective memory in context: Moving through a familiar space. Journal of Experimental Psychology: Learning, Memory, and Cognition, 43(2), 189-204. https://doi.org/10.1037/xlm0000303

Smith, R. E., \& Loft, S. (2014). Investigating the cost to ongoing tasks not associated with prospective memory task requirements. Consciousness and Cognition, 27, 1-13. https://doi.org/10.1016/j. concog.2014.04.002

Smith, R. E. \& Skinner, D. (2019). Prospective memory in context: Methods, findings, and future directions. In J. Rummel \& M. McDaniel (Eds.), Current issues in memory: Prospective memory. Taylor and Francis: Psychology Press

Strickland, L., Heathcote, A., Remington, R. W., \& Loft, S. (2017). Accumulating evidence about what prospective memory costs actually reveal. Journal of Experimental Psychology: Learning, Memory and Cognition, 43(10), 1616-1629. https://doi.org/10.1037/ $\mathrm{x} \operatorname{lm} 0000400$
Strickland, L., Loft, S., \& Heathcote, A. (2020). Investigating the effects of ongoing-task bias on prospective memory. Quarterly Journal of Experimental Psychology, 73, 1495-1513.

Strickland, L., Loft, S., Remington. R. W., \& Heathcote, A. (2018). Racing to remember: A theory of decision control in event-based prospective memory. Psychological Review, 125(6), 851-887. https://doi.org/10.1037/rev0000113

Open Practices Statement

The data and materials for all experiments will be made available by contacting the corresponding author.

Publisher's note Springer Nature remains neutral with regard to jurisdictional claims in published maps and institutional affiliations. 